\title{
The Economy between Fluctuations in Oil Revenues and Diversifying Sources of Income in Arab Countries
}

\author{
${ }^{1}$ Yun D Starchenko \\ ${ }^{1}$ Center for Education, Sumy State University, Sumy, Sumy Oblast, Ukraine, 40000. \\ ${ }^{1}$ yundstar@sumdu.edu.ua
}

\author{
Article Info \\ Journal of Journal of Enterprise and Business Intelligence (http://anapub.co.ke/journals/jebi/jebi.html) \\ Doi: https://doi.org/10.53759/5181/JEBI202101011 \\ Received 30 September 2020; Revised form 28 October 2020; Accepted 28 December 2020. \\ Available online 05 April 2021. \\ (C2021 Published by AnaPub Publications.
}

\begin{abstract}
The Economic Monitor offers an overview of key economic trends and policies over the preceding six months and discusses conclusions from recent World Bank work on Iraq, putting them in a longer-term and global sense and evaluating the impact of these developments and other policy adjustments Iraq's outlook. The macroeconomy, capital markets, and indices of human health and growth are all included. It is aimed at a broad range of people, like policymakers, industry executives, stock market players, and Iraq's analysts and practitioners. The research problem was represented by the fact that the Iraqi economy is single-source due to its dependence on the crude oil sector, which constitutes more than $(60 \%)$ of the gross domestic product. Crude oil revenues constitute more than (90\%) and neglect other economic sectors such as agriculture, industry, and tourism, whose percentage did not exceed $(30 \%)$ of the gross domestic product. The weakness of non-oil exports in the foreign trade sector is the failure of macroeconomic policies to diversify the Iraqi economy. The research aims to achieve many goals, the most important of which are: identifying the concept and indicators of diversification. As well as an analysis of the Iraqi economic structure during the period (2008-2019). A forward-looking vision for economic diversification in Iraq.
\end{abstract}

Keywords - Iraqi Economy; Rentier Economy; Oil Prices; Oil Returns; Economic Indicators.

\section{INTRODUCTION}

Economic diversification has prominent importance in the past few decades, after countries, especially oil-producing countries, realized their dependence on a unilateral resource that may affect their national economy through the lack of development plans with their integrated frameworks that ensure the achievement of positive goals and then the advancement of development indicators. Therefore, diversifying the economic base is one of the main objectives of the development process due to its economic, social, and political implications and its response to changing the existing economic structure. This requires confronting and addressing challenges and obstacles and setting up economic policies that diversify income sources. This is what many countries have pursued, achieving economic developments that have been reflected in their high rates of economic growth. Economic diversification is one of the vital strategic issues to correct those imbalances that it suffers from, especially concerning the events of transformations or structural changes in the economic structure and reduce its dependence on the sole resource. The policies, requirements, and elements of diversification require the availability of basic conditions and pillars regarding countries' material and human capacity on the gradual transition from focus to diversification [1]. The importance of the research emerges from the fact that economic diversification is of great importance in a country's economy as it is a development idea, as the structure of the economy. From this vision, diversification must be linked to the development vision raised related to the economic structure and the changes that might accompany that in the economy's structure [2-5]. It may accompany the intended changes in modifying the basic sectors' contribution, including industry, agriculture, trade, finance, tourism, the oil sector in oil countries, and logistical and knowledge services.

The research problem was represented by the fact that the Iraqi economy is single-source due to its dependence on the crude oil sector, which constitutes more than $(60 \%)$ of the gross domestic product. Crude oil revenues constitute more than $(90 \%)$ and neglect other economic sectors such as agriculture, industry, and tourism, whose percentage did not exceed $(30 \%)$ of the gross domestic product. The weakness of non-oil exports in the foreign trade sector is the failure of macroeconomic policies to diversify the Iraqi economy. A forward-looking vision for economic diversification in 
Iraq. The research aims to achieve many goals, the most important of which are: identifying the concept and indicators of diversification. As well as an analysis of the Iraqi economic structure during the period (2008-2019).

\section{RESEARCH HYPOTHESIS}

The research starts from the hypothesis that diversifying sources of income in the Iraqi economy may reduce risks and volatility and reduce unemployment rates.

\section{Diversification concept}

It is a process that refers to reliance on an increasing group of items that participate in the formation of the output. It can also be translated in diversifying export markets or diversifying sources of income away from local economic activities, i.e., income from foreign investment or diversification of sources of revenue [1].

\section{Justification for diversification}

- When the prices of exported products decrease, the foreign exchange earnings from exports decrease. This reduces the state's ability to finance imports or finance the economic development process. It reduces the risk of reduced exports for countries that depend on a single source and has a weak economic diversification degree.

- The ability of economic diversification to face crises and irregular risks in particular.

- It contributes to an increase in the rate of trade exchange; when trade is limited to one product, the decrease in the prices of that product will affect the volume of exports and lead to weak financial revenues for the state. Many goods and services lead to a decrease in losses resulting from fluctuations and an increase in the trade exchange rate.

- Increase job opportunities since diversification stimulate economic growth, achieve sustainable development, and increases the degree of interdependence and interdependence in the economic sectors, leading to an increase in the demand for labour and generates job opportunities and thus reduces unemployment rates [2].

\section{Types of diversification}

\section{Horizontal diversification}

It is diversification that depends on creating a new product sector that creates wealth, and it is the most difficult strategy because it needs new activities in the economy, as it is called the distribution of investment on tools of the same class, i.e., for example, the petroleum sector [3].

\section{Vertical diversification}

It is the other type of diversification, which depends on adopting a policy of expanding the chain of manufactured products in the same sector to form an integrated sector, as it is called the distribution of investment to various sectors such as agriculture, industry, services or different classes of investment tools such as stocks and bonds.

\section{Diversification objectives}

- Bringing about a series of structural and structural changes in the economy, seeking to get out of the state of decline in sources of income and reduce the steady and excessive dependence on one commodity.

- Achieving self-sufficiency in goods and services, increasing exports, reducing dependence on abroad for importing consumer goods, providing job opportunities, and improving living standards.

- Enabling the private sector to play an important and larger role in the economic process and reduce the state and public authorities [4].

\section{Diversification policies}

\section{Foreign direct investment policies}

It is one of the modern economy branches indispensable for any investment project, whether it is already in place or just an idea on the table. Investment operations flourished during the fifties and even the beginning of the seventies the last century. However, most countries were on the path of growth, so the industrialized countries accelerated to obtain investment concessions in prospecting and searching for wealth. The quality of investments developed as we see it [5].

\section{Investment Policies}


It is a set of general principles and rules in addition to the central directives and measures that govern the investment process within the national economy according to size, investment priorities, distribution of sectoral and regional investment, nationality of the investment, its ownership, its production strategy, and the type of sources of financing the investment activity [7].

\section{Privatization Policy}

Privatization is defined in the legal sense as an act of economic sovereignty, and one of its forms concerned with the legislative authority alone. It is a process by which the ownership of public projects owned by the state is partly or transferred to private ownership represented by legal or natural persons to achieve social necessities and economic and political development [8].

\section{Structural reform policy}

The diversification of the production structure aims to find new sectors that attract labour and achieve economic stability. This process requires the development of investment programs and plans to diversify sources of income and reduce the risks of dependence on oil. It is possible to benefit from the experiences of some countries in the field of economic diversification. Countries are taking advantage of their advantages for economic diversification [9].

\section{Industrial Policy}

It is a set of measures that governments resort to implementing specific policies through several means, such as customs tariffs or fees and the exchange rate. In addition to bank loans, subsidies and interest rates influence industries' or industrial behaviours of the production or investment sector or others, thus encouraging exports or Local industries to replace imported industries [10].

\section{THE IRAQI ECONOMY}

\section{The reality of the Iraqi economy}

The Iraqi economy represents a model for a developing economy as the main source for the formation of national income. Then it is considered a rentier economy, in which the state has adopted a central planning system for many years. During previous periods, many developments emerged that reflected their effects on the Iraqi economy, the most important of which was the increase in oil revenues and the distinction of the Iraqi economy. After the year (2003), a constitutional vacuum occurred due to the institutions dismantling the Iraqi state after the American occupation and the resulting imbalances. And distortions after the occupation process in (2003), exemplified by the absence of clear strategies for economic development, whether production or service, in the absence of a free economy system following the Iraqi constitution. Is it a capitalist or a socialist, so it is noticed that there is an uncertainty prevailing in the entire economy and the resulting waste of material and human capabilities alike [11].

\section{Characteristics of the Iraqi economy [12]}

- Increase in the contribution of the oil sector.

- The dominance of the public sector.

- Adopting the inclusive economic model.

- The weakness of the private sector.

- The disruption of foreign trade.

- Structural imbalances.

\section{The nature of the general structure of the Iraqi economy}

The Iraqi economy consists of three main sectors that form the general framework for the structure of the Iraqi economy:

\section{Commodity Sectors}

This sector consists of (manufacturing, agriculture, forestry, fishing, mining, quarries, electricity, water, gas, and construction), as it witnessed a continuous increase during the period (2008-2013) amounting to (56.631, 87.166, 125.537, 126.435, 115.256). 73.990 billion dinars, respectively, due to the growth in oil revenues and the rise in crude oil prices, reflected in its contribution to the gross domestic product. In 2014-2015, the commodity sectors retreated, reaching (62.027 - 116.740) billion, respectively. Dinars, respectively, and the reason is due to the sharp decline in crude oil prices, which was reflected in decline in the value of oil output, and this is evidence that the decline in the oil sector leads to a decline in the commodity sector, and in the period (2016-2019) witnessed a continuous increase to reach 
$(150,516,143,666,143,636)$. (143.169) billion dinars, respectively, due to the rise in crude oil prices in the global market, the improvement in the security situation and the liberation of the western regions from ISIS gangs, which helped increase commodity activities and increase the GDP, and despite the fluctuations in this sector, it remained the leading and controlling sector. Growth and movement of $\mathrm{n}$ The gross domestic product in the Iraqi economy [13].

\section{Distributive sectors}

This sector generally consists of the following activities: transport, communications, retail and wholesale trade, restaurants, hotels, banks, and insurance. During the period (2008-2013), the value of the distribution sectors reached $(19,368$ - 19,960 - 23,975 - 27,086 - 38,302, 43,664) billion dinars, respectively due to the transformation The market economy, which witnessed a gradual improvement as a result of the shift towards a market economy, which increased the role of the private sector. Moreover, the tourism development that Iraq witnessed after the US occupation led to an increase in hotels and restaurants throughout Iraq due to the improvement in the living conditions of the Iraqi individual during this period. The improvement in the role of the banking sector in the economy as a whole as a result of the availability of liquidity and the desire of the monetary authority to increase the level of economic activity, which contributed to increasing the contribution of this sector to the formation of the gross domestic product [14]. The transport and communications sector also contributed to the overall improvement of the distribution sector. After 2003, foreign telecommunications companies entered as investors in the telecommunications sector to provide wireless communication services lacking in Iraq before this period. Moreover, the transport sector has developed. Its contribution has also increased due to the large domestic trade exchange and the development and expansion of the airline and land network through expanding the air navigation network. For the years (2014-2015-2016), the distribution sectors witnessed a remarkable decline, reaching $(42,937$ - 38,643 - 30,519) billion dinars, respectively. This is due to the significant decline in crude oil prices, reflected in oil revenues and then in all sectors. The economic period, and in the period (2017-2019) witnessed an increase to reach $(32,608$ - 33,608 - 35,203) billion dinars, respectively, due to the decline in the price of crude oil in the global oil market, which was reflected in the increase in economic activities. This is considered a five-year low in light of the high oil revenues that reached their peak during this period, which should be reflected more positively.

\section{The service sector}

The housing sector includes the government services sector such as public administrations, defence, health works, educational and medical services, and the other services sector such as social services and personal services related to education, entertainment and education, education services and transportation. The services sector differs in that it does not produce a specific commodity, but rather its role is limited to distributing the necessary services necessary for the production process, and this sector has great importance. It is necessary to develop its development to achieve joint integration with other sectors to form the gross domestic product. This sector consists of the following activities / (housing, public utilities, services such as education, health, security, and defence) [14].

Despite the continuous growth in this sector, the volume of services provided does not match the reality of the Iraqi economy, which is characterized by high rates of human growth. It was determined by the government to achieve this and failed to implement it than to solve only a small part of this problem. As for the reality of other services such as health and education, Iraq does not have the simplest elements of quality standards in education, which made it ineligible to enter the global evaluation of universities. As for the reality of the health sector, it is in a state of continuous decline, as the percentage of individuals deprived of health services reached (21-22\%) of the total members of society, as well as social solidarity because the reality of poverty in Iraq has increased dramatically among members of society, amounting to approximately (22.9\%) Of the total society, as well as security, it has been unstable since (2003) until the present despite the high military and security spending.

The service sectors witnessed a continuous increase during the (2008-2013) to reach $(34,437$ - 36,091 - 45,075 $45,679-52,937-60,198)$ billion dinars, respectively to the continuous rise in crude oil prices. The improvement in the economic and security situation and the increase in financial allocations to the services sector increase Oil revenues, improve the economic situation and a continuous financial surplus in the general budget. In the period (2014-2017), it witnessed a continuous decline, reaching $(57,831$ - 65,831 - 26,781 - 26,739) billion dinars, respectively, due to the sharp decline in oil prices in the global market, which was reflected in decline in oil and general revenues that led to the creation of a financial deficit in the Iraqi budget. In addition to the deterioration of the security situation and the entry of ISIS gangs into Iraqi lands, especially in the northern regions, which led to the difficulty of production in the sectors and thus began to decline. In the years (2018-2019), it rose to / $(27,230)$ billion dinars, respectively, due to improved security and economic situation, the liberation of Iraq from ISIS gangs, and the facilitation of production between Iraqi cities, as shown in table 1. 
Table 1: The activities that make up the gross domestic product of one billion dinars

\begin{tabular}{|c|c|c|c|c|c|c|c|}
\hline \multirow[t]{2}{*}{ Years } & $\begin{array}{l}\text { Sum of the } \\
\text { Commodity } \\
\text { activities }\end{array}$ & $\begin{array}{l}\text { Sum of the } \\
\text { Distributive } \\
\text { activities }\end{array}$ & $\begin{array}{l}\text { Some of the } \\
\text { service } \\
\text { activities }\end{array}$ & GDP & Rate & Rate & Rate \\
\hline & 1 & 2 & 3 & 4 & 01:04 & 02:04 & 03:04 \\
\hline 2008 & 87,166 & 19,368 & 34,437 & 162,062 & 53.78 & 11.95 & 21.24 \\
\hline 2009 & 56,631 & 19,960 & 36,091 & 139,732 & 40.52 & 14.2 & 25.82 \\
\hline 2010 & 73,990 & 23,975 & 45,075 & 158,521 & 46.67 & 15.12 & 28.43 \\
\hline 2011 & 115,256 & 27,086 & 45,679 & 217,327 & 53.03 & 12.46 & 21.01 \\
\hline 2012 & 126,435 & 38,302 & 52,937 & 254,225 & 49.73 & 15.06 & 20.82 \\
\hline 2013 & 125,573 & 43,664 & 60,198 & 273,587 & 45.8 & 15.95 & 22 \\
\hline 2014 & 116,940 & 42,937 & 57,831 & 260,065 & 44.96 & 16.51 & 22.23 \\
\hline 2015 & 62,027 & 38,643 & 65,169 & 207,908 & 29.83 & 18.58 & 31.34 \\
\hline 2016 & 143,169 & 30,519 & 26,781 & 203,900 & 70.21 & 14.96 & 13.13 \\
\hline 2017 & 143,636 & 32,097 & 26,739 & 226,000 & 63.5 & 14.2 & 11.83 \\
\hline 2018 & 143,666 & 33,608 & 27,230 & 251,064 & 57.21 & 13.38 & 10.84 \\
\hline 2019 & 150,516 & 35,203 & 27,808 & 262,132 & 53.78 & 5.8 & 4.58 \\
\hline
\end{tabular}

Source: Central Bank of Iraq, annual reports, for the period (2008-2019).

\section{Reasons for the failure of diversification in the Iraqi economy}

\section{The deterioration of the industrial sector}

The relative contribution of the industry to the formation of the gross domestic product began to decline for the following reasons [14]:

- The increase in imports after the CPA decides to freeze the customs tariff law and apply the Iraq reconstruction tax instead of it, at a uniform rate of (5\%) on all imports.

- The opening of markets after 2003, the influx of imported foreign goods, the emergence of severe marketing problems in front of the industrial sector companies, and the reluctance of government institutions to buy national industrial products.

- The high level of industrial costs and raising the subsidies provided to production inputs before 2003 .

- A high percentage of private-sector factories stopped working and closed after 2003 due to their unfavourable security and economic conditions.

- The industry has not played a major role in employing human resources in Iraq, as the total workforce in the industry in all its sectors (public, mixed and private) is estimated at around 500 thousand workers, and $40 \%$ of the sector companies depend on government aid to pay wages. At the same time, mixed sector companies and private sector companies do not enjoy this aid.

\section{The agricultural sector deteriorated}

The agricultural sector in Iraq has suffered a significant decline compared to the actual percentage before 2003. One of the most important reasons that participated in this decline was the interruption of government support in financing and requirements and the absence of a general agricultural plan or a sober organization, so one of the most important reasons that led to the decline of the sector Agricultural [15]:

- The Iraqi economy's dependence on oil as the only source of wealth is an immediate and not strategic choice, neglecting other sectors, including the agricultural sector.

- Water scarcity and desertification in common land areas due to climate, weather conditions, and global warming contributed to rainfall. 
- The catastrophic failure to implement the Agrarian Reform Law No. 30 of 1958, and what happened after that, the scourge of Iraqi agriculture.

- The lack of financial allocations from the federal government and local governments to support the agricultural sector in all its details has led to the deterioration in this vital sector.

\section{Tourism sector}

Tourism is an important source for earning hard currencies or foreign currencies, as tourism is an inexhaustible financial resource, and sometimes it is an essential resource for some countries. Tourism improves the balance of payments, provides new job opportunities, contributes to solving unemployment, and provides many investment opportunities, but there are many problems. And the challenges facing the tourism sector in Iraq, including [16-17]:

- The weakness of the media side, which contributes effectively to awareness and education for this sector.

- The absence of specialized companies that take upon themselves to introduce tourists from home and abroad to tourist sites, whether heritage or religious, and their historical significance.

- High air transportation fares for arrivals to Iraq onboard planes coming from countries worldwide, anticipating the potential risks to the plane in Iraq.

- Neglect of archaeological sites and most of them have turned into military sites, especially Babylon and the Ziggurat ruins. There is a failure in maintenance, restoration and reconstruction, and the indefinite postponement of many excavations. And the absence of a programmed system to visit and increase the attraction of tourists to these sites.

\section{Failure of economic policies}

Most of the countries that were economically affected by the symptoms of the Dutch disease (it is a state of laziness and functional slackness that afflicted the Dutch people in the first half of the last century (1900-1950) after the discovery of oil in the North Sea) in general and developing countries in particular, including Iraq, and the reason is not There are clear goals and strategies for development [18]. In light of this reality, which witnesses the floundering of economic policies, oil and natural resources have not been directed to the important channels that would bring about a fundamental change in the traditional economic structure in which these countries live, as it is assumed that natural resource revenues will be used as a strong impetus through the ability to provide several resources. Commensurate with the investment needs to start and move towards self-growth and make structural changes in the national economy. However, in the absence of an appropriate development strategy and misallocation of natural wealth revenues, failure will be the share of development. The economy remains unable to carry out its burdens relying On the rentier returns, thus losing the opportunity to move forward. The availability of development needs to achieve economic development goals must be the production of the targeted amount of goods and services with the determination of what is allocated to consumer and productive goods, or the financial allocations can be estimated by the required economic needs. However, the problem that developing countries face is the absence of a clear economic policy. The lack of optimal and efficient use of economic resources, and not the scarcity of resources to finance the economic development process.

\section{Requirements for economic Reform in Iraq}

\section{The first requirement-reforming the structure of the Iraqi economy-Reforming the industrial sector}

- Organize a comprehensive national campaign to encourage citizens and government institutions, stimulate the national drive to acquire local products, promote Iraqi industrial establishments, and rehabilitate those that enjoy economic viability.

- The participation of local and foreign investors in rehabilitating the establishments that need large sums of money, expertise and high technology within the framework of the partnership mechanisms between the state and the private sector.

- Work to restructure companies and factories according to the market economy and define projects that can be allocated.

- Working on preparing draft laws that contribute to creating an appropriate environment for investment, whether local or foreign and consumer protection laws, competition and product protection.

- Work on enacting and enacting new laws and amending the repealed laws for organizing all industrial sector workshops in the country.

- Combating corruption in governmental institutions, especially those of the Ministry of Industry, activates strict laws and procedures that limit the escalation of this deadly epidemic [19]. 


\section{Reforming the agricultural sector:}

- Work to develop comprehensive strategic plans for advancing the agricultural situation in Iraq, primarily responsible for the ministries of planning, agriculture and water resources, in cooperation with local governments.

- The necessity of encouraging investments in this sector and creating a stimulating investment environment.

- Disseminating agricultural techniques to raise the level of agricultural production through scientific research and agricultural extension centres, by spreading modern irrigation techniques to reduce waste in water use, disseminating technological techniques to produce improved seeds and innovative varieties, spreading chemical technologies such as fertilizers and agricultural pest control materials.

- Emphasis on increasing the productivity of one acre by using the technology package and intensifying production.

- Reclamation of agricultural lands commensurate with the size of desertification.

- Addressing the water problem, especially by concluding bilateral agreements with the countries providing it.

- The necessity of introducing modern technology widely in all agricultural fields and introducing modern agricultural mechanization to save effort, human resources and time, and ensuring the quality of the agricultural crop produced and increasing its quantity [20].

\section{Tourism sector reform}

In Iraq, the tourism sector can be relied upon to advance the process of economic and social development, increase public revenues, and contribute to creating a sector that can exert a positive impact on the joints of the national economy through, and among the most important components of the advancement of the tourism sector in Iraq:

- Work on preparing a comprehensive, clear-cut development plan for developing the tourism sector.

- The need to work to stimulate the private sector to enter and invest in this sector.

- Spreading tourism awareness among citizens, such as seminars and conferences, preserving the environment, and everything related to extinguishing a civilized image of the country abroad.

- The fields of transportation and transportation, including government investments to establish civil airports, river ports, etc., and the construction of land roads designated for investment.

- Areas of tourist accommodation, including hotels, rest houses, complexes, villages, and tourist cities, etc., especially in places that have a comparative advantage such as religious tourism thanks to the presence of the shrines of the Muslim imams, peace be upon them, in Najaf, Karbala, Baghdad, Samarra, etc. [21].

Reforming the transport sector:

Therefore, a set of measures are required to increasing the activity of this sector to achieve an increase in sources of income within the framework of economic diversification, among which are the following [22]:

- Improving the efficiency and performance of the national air carrier through global partnership with economic efficiency to comply with international standards by building alliances with solid international companies operating in this field, as well as upgrading national training institutions to meet international standards, as well as working on establishing new airports and rehabilitating and developing airports. The current method of adopting partnerships with foreign companies specialized in this field.

- Improving the current road network condition, increasing its capacity, raising the level of safety and security for its users, protecting it from harm, and developing and securing public transport within and between cities to make it fast and environmentally friendly.

- Modernizing and developing the railway system raises its operational capacity, reduces the journey time, ensures safety, and strengthens Iraq's geographical location as a link between East and West.

- Equipping the railway network with modern trains, new cars and trucks, transport passengers and goods to meet the needs of the market and the national economy, and rehabilitate the existing ones.

- Modernizing the communications system in the current railway network, including the satellite organization that allows trains to be tracked at any time to avoid accidents and breakdowns on trains.

\section{Electricity sector reform}

It is one of the economic sectors that distribute the gross domestic product in Iraq. The current transmission lines suffer from many bottlenecks as the electrical loads exceed the capacity of the transmission network. Hence, it is 
necessary to extend additional lines and establish transfer stations to improve the level of this organization and increase its ability to deliver electricity better. The completion of many projects in this sector, which included several secondary stations (400 and 132) kV, transmission lines (400 and 132) kV, and cables (132) kV. This sector also suffers from load growth by (7\%) due to unconsidered breaks in residential units, as well as bulldozing agricultural lands and converting them into residential units, illegal encroachments on the electrical network and the lack of system maintenance work [23]:

- Financing and the budget: The need to increase the budget allocations for electricity according to the need indicated therein. If this is not possible, the option that would remove pressure on the basic budget remains to allow the private sector to build some of the required generation sectors.

- Converting simple gas stations into a combined unit is expected to add a capacity of (4584) MW.

- Completing the production units under construction, including gas stations and steam stations, to reach a total designed production capacity of (53147) MW.

- Increase the per capita share of electrical energy to reach (4041) kilowatts. One hour and by absorbing the added generation capacities by rehabilitating and developing transmission and distribution networks.

- Improving the efficiency of the electrical system by reducing domestic consumption and wastes in the electrical systems of the distribution sector to be by (30\%) of the available energy.

- Improving the quality of services provided to consumers with their categories (household, agricultural, industrial, commercial, government) increases the annual daily rate of hours for the supply of electrical energy to be at a rate of (20) hours/day.

Banking system reform

To reform the banking system through several reforms [24]:

- Providing security and economic stability because the banking sector is closely linked with them, as the banking sector cannot function normally and the environment unless there is security stability and economic stability, which is an important factor in banking business development.

- Work to use the latest technologies in the field of the banking system by developing a strategic plan according to the available capabilities, linking banks with the Central Bank of Iraq through the electronic communication network and craft stations, and efficient and robust modernization of the financial infrastructure, including the ability to make payments electronically inside and outside Iraq.

- Adherence to the approved international standards such as capital adequacy and financial disclosure of banks' financial statements reflects greater transparency in the Iraqi banking business.

- Restructuring the banking sector by encouraging merger between banks, especially small ones, as well as with foreign banks to establish large banks capable of expanding them to provide new services to become a basic and effective pillar for economic growth, moving away from monopolizing some banking operations from private banks and adopting banking marketing to face competition.

Building and housing sector reform:

The most important components of reforming the housing and buildings sector:

- Issuing new legislation and laws and amending the existing ones contribute to accelerating the production of housing units and removing bottlenecks in existing housing and residential neighbourhoods.

- Encouraging non-governmental banks to finance the stalled housing projects directly and activating the lending policy for the beneficiaries of residential complexes under implementation or stalled.

- Activating laws and legislation to address abuse and randomness.

- Urging the governorates to actively participate in financing part of the housing complexes under construction or stalled from their financial allocations earmarked for regional development programs.

- Encouraging large private companies operating in the country to contribute to financing and implementing residential complexes by establishing low-cost homes instead of slums and transgressors as part of the community service provided to the community.

Service sector reform

To achieve the desired goals of this sector, the matter requires the following application [25]: 
- Belief in partnership between the public and private sectors in managing and providing public service must be based on human rights.

- The need to privatize the service facilities that stand alone and unable, through their budget, to reform and finance them to preserve the vital and influential effort for this sector in the development process and to ensure the provision of services and provide them with quality and distinctive quality for all members of society. Tourism facilities such as hotels and restaurants can be a fertile field for the privatization of projects.

- Developing the banking system and using the best technology in financial transactions.

Free Zones

- Interest in and investment in the infrastructure project for free zones and rehabilitate the free zones in Al-Qaim and Khor Al-Zubair.

- Work to stimulate industrial investment for all free zones, as it constitutes a basic and important pillar in investment, and it comes in the first place ahead of other activities.

- Opening new horizons to ensure the revitalization of the investment movement in the service of the public interest and coordination with the Relations and Media Department in the body, to avoid conflict between the procedures of the two bodies that work to attract investors in the absence of coordination between them and each of them has its regulations and instructions.

- Work to activate the traffic trade (transit) because of the geographical location that Iraq enjoys, making it the most important port, which will support the Iraqi ports and the transport sector and other sectors.

- Paying great attention to the media aspect of the free zones by adopting global promotional and marketing campaigns that adopt various media outlets, Iraqi embassies, corporations, and institutions participate in that effort in various parts of Iraq. Citizens are also encouraged by various means to deal and interact with them and increase the front and back networks between these Regions and all other regions of Iraq.

\section{A forward-looking vision for economic diversification in Iraq}

The development of the industrial sector

The most important treatments in the industrial sector can be mentioned [26]:

- The nature of the Iraqi market: The Iraqi market can be considered encouraging to attract foreign investment, as it contains the purchasing power of the population and the potential for growth of those variables and the growth of the Iraqi economy in addition to the market capacity and the ability to substitute the importer of imported goods with the local product by companies.

- Human resources: Iraq has an unemployed workforce that possesses the skills, competencies, and experiences that qualify them to work for foreign companies at low wages than the labour force coming from abroad.

- Access to markets: It is possible to benefit here from free trade areas, and trade agreements concluded between Iraq and neighbouring countries (Turkey, Iran, Syria) in the food, textile and leather industries by taking in the production units wells about the available opportunities and emphasizing the production input provided that it is established in Iraq.

\section{Development of the agricultural sector}

The most important treatment methods in the agricultural sector can be mentioned [27]:

- Improving irrigation practices: The programs and expansion of drip and sprinkler irrigation techniques will reduce the expansion of water and reduce salinity, and by taking into account the high cost of such an investment, the focus on the agriculture sector in greenhouses gives the greatest possibility for initial success, that the introduction of modern irrigation techniques in this activity will They provide the dissemination of useful knowledge and will create processing networks that will equip them to allow a wider application of this application in agriculture over time.

- The basic need regarding input processing is updating and expanding seed varieties. There is a need to direct initiatives towards creating more effective means of approving new seeds by enhancing the Ministry of Agriculture's capabilities and liberalization. Government companies do not derive from playing a role. Dominance in distortionary ways, and so does the fertilizer market needs support.

- Focusing on extension system programs and developing and expanding private sector service centers has proven its worth in providing technical knowledge for workers in the agricultural sector. 
- Availability of program areas: These could greatly enhance productivity, product quality, and market composition, increasing farm incomes, expanded employment opportunities, food security, and an improvement in the Iraqi trade balance.

\section{Development of the Tourism Sector}

The most important treatment methods in the tourism sector to remove obstacles can be mentioned [28]:

- Improving the quality and provision of tourist shelters.

- Benefiting from international expertise and experiences in the field of tourism and participating in training courses to develop the competence of workers in this sector.

- The necessity to expedite the development and introduction of electronic programs and modern technologies in managing the establishment and tourism facilities and building databases and statistics based on modern electronic systems and programs in tourism statistics and related matters.

- The necessity of issuing a tourism law and unifying independent entities that link their work with the tourism sector (Ministry of Culture, Ministry of Tourism, Tourism Authority in Iraq).

\section{The development of the health sectors}

Public health is an integral part of economic and social development, and these two developments depend on health. Most international conferences concerned in this regard have emphasized the social, economic and environmental determinants of health. The health status of the Iraqi population has suffered major setbacks due to decades of war, international sanctions and the American occupation due to the sharp decline in The domestic product, and then the decrease in spending on health, and we can mention the most important treatments in the health sector, namely:

- Developing the infrastructure and the level of services and environment for health institutions to reach quality services.

- Building partnerships between the public and private sectors and supporting them in construction, sustainability, management, and efficiency.

- Developing nursing colleges and institutes, encouraging their turnout, developing medical institutes, and increasing the number of their graduates.

- The use of all mass media means to deepen the citizen's health awareness, in addition to the health education that educational institutions, civil society organizations and local councils can provide through various courses, seminars, and bulletins.

\section{Development of the Education Sector}

To address educational problems, it is necessary :

- Expanding and modernizing buildings and equipment.

- Reforming the governance of the educational sector.

- Increase teachers' capabilities and administrative capabilities.

- Improving higher education curricula.

- Launching evening studies for learning.

- Professional software update.

The transport and communications sector

The most important proposed treatment methods for the transport and communications sector can be mentioned :

- Improving the workforce's skills included in the activity and through a development initiative that would improve the governance and management of all ports in Iraq.

- The Ministry of Transport and Communications proposes investment projects with foreign companies to establish the highway line linking Iraq internally with the outside.

- Establish a fund to improve the infrastructure to develop roads, bridges, facilities, and ports.

- The necessity of cooperation between Iraq and the neighbouring countries, such as establishing a large port in Basra to transport the containers that will connect Basra to Europe via Turkey, is less costly and safer than other routes through the Suez Canal and maritime piracy. 


\section{Following a policy to reform imports of goods and services in Iraq}

The import substitution strategy goes back to (Prebisch), as he noticed that the elasticity of demand for products of developing countries (primary products) tends to decrease. In contrast, the opposite happens to the elasticities of demand for products of developed countries (manufactured products), as they tend to rise, which works against The rate of international exchange for developing countries or countries of the ocean, and in the interest of developed countries. This policy aims to either replace imported, domestic products or encourage industrial exports, or both.

\section{Expansion and development of the private sector}

The work to develop the private sector and increase its efficiency must start with the state's intervention in the rules, institutional structure, market institutions regulating the sector's work, anti-monopoly laws, consumer protection, and workers' rights. For this sector to take an important and distinct role that contributes to the diversification of the Iraqi economy, it is necessary. Work to achieve a package of reforms as follows:

- Adopting an integrated economic policy for the reconstruction of Iraq and providing the best conditions and requirements for the governmental, private, and mixed sectors, everyone contributes to the reconstruction process and the development of all economic sectors according to his capabilities and capabilities.

- Building a banking system that works with a clear mechanism in terms of facilitating the process of financing and lending, speeding up completion (especially in financing small and medium enterprises) and providing more services, especially in the field of clearing and documentary credits, with conditions for the process, and avoiding red tape, corruption and administration.

- Work to involve the private sector, including large companies and small and medium enterprises, to restructure public companies.

- Improving the productivity and competitiveness of small and medium enterprises.

- Work to develop industrial and technological zones, business incubators, business development centers, and other similar initiatives.

- Increasing private sector investments in the basic economic and development sectors.

- Creating a program to provide opportunities for the private sector, including large companies and small and medium enterprises, to work with public companies.

- The necessity to establish a national fund to support and encourage private investment or establish a bank for the development of the private sector or both ensures private investment, especially in productive projects that contribute to employing the largest possible number of workers. It must have branches in all regions of Iraq whose mission is to finance small projects; since there is a need for special care for micro-projects, private activity in Iraq is dominated by the individual, small, unorganized sector.

\section{Attracting foreign direct investments}

In light of the great economic challenges that the Iraqi economy is going through, it has become necessary to deal with foreign investments as a reality that must be interacted with as a very important source for financing the needs and requirements necessary to implement production and development plans. And from the other, foreign investments are a source of technology transfer and experience, openness to international markets, and the possibility of access to it, and perhaps the most important requirements for attracting local and foreign investments alike to provide an appropriate investment environment is:

- Providing security and stability critically

- Providing legal and legal frameworks

- Providing qualified staff

- The creation of investment information centers represented a database on developments in the investment process. This information is provided by ministries and sectoral bodies without restrictions and full transparency

- Restructuring the institutional framework of state agencies and activating civil society institutions

- Creation of institutions that support the market economy

- Job and training opportunities granted to the Iraqis

- Supporting the project in the growth of national product and per capita income

\section{Reform of the Customs Administration}


The customs administration is considered one of the most important sources of funding on which it can be relied upon in achieving the state's directions to reduce dependence on oil revenues and deepen the concepts of Reform as stated in the International Compact document that aims to achieve sustainable development by strengthening economic growth and diversification in line with the agreement concluded by Iraq with the International Monetary Fund. , That the most important thing that is observed on the customs administration in the country is its low efficiency, the expansion of the phenomenon of tax evasion, and then the reduction of restrictions on importing foreign goods, which leads to an increase in the level of import of various goods with a significant decrease in the level of government revenues, as it is not commensurate with the values of Imported goods, on this basis, the reform process requires the following:

- The application of the Customs Authority, the risk mechanism, is a mechanism that enables the customs administration to establish an early system and a defence network to protect the economy and markets from the risks of various economic crimes.

- Transparency in information and laws. A customs administration must notify merchants, exit agents, and citizens of customs procedures in light of transparency and participation, give them extensive knowledge of what is required of them, and the stages of completing the transaction to avoid corruption cases.

- Work to remove all distortions in the customs tariff structure and revitalize its structures to reduce tax evasion.

- The necessity to develop the customs administration by developing human resources and developing training programs for workers and modern technology reduces paperwork to reduce corruption.

\section{Free Zones Development}

Free zones play an important role in the economic activity of any country by increasing the volume of trade exchange and promoting comprehensive economic development and its role in activating investment activity in its various sectors (commercial, industrial, and service). Free zones are distinguished as important sources for financing public revenues and diversifying sources of national income. The importance of free zones is that they are an open gateway to attract investments and attract local, Arab and foreign capital, in addition to the role of free zones in investing all energies and natural and human resources and contributing to the development of the surrounding areas, creating more job opportunities, providing services and providing the necessary infrastructure for this:

- Transfer and indigenize technology and technical and administrative expertise.

- Creating new job opportunities for national workers to raise their efficiency and skills.

- Activating sectors are feeding the free zone activity, such as transport, transportation, insurance and banking.

- Using local materials and resources to achieve economic interdependence between the free zones and the national economy.

- Enhancing the development experience in Iraq by examining the industrial experiences of foreign companies investing in the free zones.

\section{Financial Market Reform}

It is well known that the experiences based on implementing reforms in various countries of the world that are on the path of transformation are that financial liberalization does not succeed only when the preconditions for the entire reform process are met to achieve economic, financial and monetary objectives to reach comprehensive economic stability that requires wide-ranging reform measures, including the establishment of markets. In the transition and developing economies, it is of particular importance as it is one of the characteristics of an emerging and developed market economy:

- As an essential support and management mechanism for economic transformation.

- Its role in facilitating local and foreign savers and the availability of various financial tools that encourage saving and fundraising, especially small emerging companies, creating a mechanism for control, guidance on project behaviour and achieving discipline in management.

\section{A forward-looking vision for financial and monetary Reform}

\section{First: Rationalizing public spending}

Public spending reflects the state's economic and social policy following the objectives of development plans. Then, reforming the structure of public expenditures will lead to achieving public welfare and progress. Public expenditures are the main source for providing services to satisfy the public needs that we urgently need, especially today. The process of reforming public spending in Iraq targets both current and investment spending. Still, the share of investment spending in expansion is usually much less than current spending due to the state's commitment to society to provide what achieves 
economic and social development such as salaries and wages in spending, and despite the expansion in achieving The goals that the state seeks to achieve requires the state to reduce the volume of current government spending following practical measures to achieve economic, political and social goals simultaneously by directing the reform process as follows:

- Determining public spending priority, both investment and current, as government spending focuses on providing priority services such as education and health, while investment spending is directed towards successful investments that provide greater added value in the economy.

- Working on evaluating the government's financial performance and verifying that it directs the goals set for it and activating the role of oversight.

- Working on setting several standards and rules that limit the spending of financial resources on economic activities that the private sector can do better, and directing the state's role to take upon itself the fulfillment of its basic functions, which are defending the homeland, protecting its borders, and providing social services.

\section{Second: Reforming the Tax System}

Activating the role of imposing taxes in Iraq occupies the first task. It has precedence in diversifying non-oil sources of income to support the preparation of the general budget and diversify its sources of resources in light of the serious challenges in oil prices and their near-certain collapse. As follows:

- Iraq Reconstruction Fee.

- Corporate income tax.

- Employee income tax.

- Interest income tax.

- Revenue tax for companies and public institutions.

- Fees for services.

- Contribution tax of retirement deductions.

The process of activating the contribution of tax revenues requires making a total of reforms and can be summarized as follows:

- The government needs to undertake real reforms in the tax system and promote it to a level that achieves its objectives, foremost among which is the financing objective of the general budget.

- The transition to a comprehensive tax system characterized by high flexibility allows the tax administration to act and change tax rates, tax bases, and personal allowances in proportion to the prevailing economic situation so that the tax policy can direct the economy towards the activities desired by the state.

- Activating the role of taxes as a non-oil source in financing the state's general budget.

- Carrying out fundamental and serious reforms in the tax system by reconsidering the tax laws.

- Raising the efficiency of tax collection, combating tax evasion, and improving the efficiency of tax administration.

Activating the collection of taxes by:

- Increasing the Iraq reconstruction fee and not keeping it at 5\% is currently applied.

- Increasing the fees collected from public sector revenues (electricity fees, subject to availability, drinking water fees, health services fees, car registration fees, weapons possession fees, import licenses).

- Activate sales tax.

- Activating the imposition of customs tariffs.

\section{Establishing Sovereign Wealth Funds}

The concept of sovereign wealth funds is to cut off oil revenues and reuse them as an alternative to low oil prices or oil depletion. Most oil-producing countries benefit from financial surpluses in times of crisis or transfer part of those revenues to future generations after the depletion of raw materials. Most of the oil-producing countries have pursued different policies to manage financial surpluses under different names for the first time in the financial arena in the fifties of the last century before. The International Monetary Fund defines sovereign wealth funds as the government's private investment funds to retain foreign assets for long-term purposes. The government owns these funds, and sovereign wealth funds are classified according to the International Monetary Fund into four forms: 
- Revenue stabilization funds designed to protect economies from fluctuations in raw materials.

- Provident funds for future generations.

- Funds for financing economic and social development.

- Governmental retirement funds to meet emergency liabilities for which insufficient funds have not been allocated in the state's general budget.

Directing the monetary and fiscal policies in a manner that encourages investments and reduces the risks of inflation through:

- Control of inflation by reducing domestic demand for goods and services.

- Renewal of foreign competition to the economy would improve the balance of payments, as real interest and exchange rates would attract foreign capital and improve the current account position in the balance of payments.

- Achieving greater effectiveness in allocating resources.

- Attracting foreign investments.

- Increase the level of saving.

And reforming the interest rate and exchange can be achieved in one of two ways:

- The first method is to allow nominal interest and exchange rates to be determined by market forces.

- The second method: setting interest and exchange rates through administrative control flexibly and responsively with market conditions.

Following the second method for countries that do not have advanced financial markets, including Iraq, and in this case, rising interest rates leads to an increase in bank deposits, and this would reduce or reduce the speed of money circulation. It is noticed that reducing the rate of demand growth in this way with a policy An appropriate exchange rate is necessary to reduce inflationary pressures.

\section{Reforming the financial and banking system and activating its role in developing the Iraqi economy:}

The banking sector occupies a major role in mobilizing economic resources and financing economic development. To advance the Iraqi banking reality and make it a true contributor to the economic development process, reforms must be undertaken, which we summarize as follows:

- Providing a politically, economically and socially stable security environment for banking.

- The necessity of linking banking reform with the economic reform program.

- Adherence to international standards, including the standard of capital adequacy and financial disclosure for banks, reflects a greater degree of transparency in Iraqi banking.

- The necessity to expedite using the latest banking methods and innovations regarding banking tools generate new banking services provided by banks and international financial institutions, such as the electronic payment method.

\section{CONCLUSION}

The economy suffers from a weak production base due to the decline and decline of the contribution of the agricultural and industrial sectors to the gross domestic product and its almost complete dependence on the oil sector, which constitutes more than $(60 \%)$. The weakness of the private sector and private investments, the state's lack of support for the private sector, and full dependence on government employment. Unemployment rates are constantly increasing in the Iraqi economy despite a budget surplus. Failure of economic policies is one factor that led to the failure of economic diversification in Iraq. Administrative and financial corruption is one of the most important factors that led to the failure of diversification and economic development in Iraq and parties' control over most state decisions.

\section{References}

[1]. Pramatari, G. Doukidis and P. Kourouthanassis, "Consumer Driven Electronic Transformation" in Towards 'smarter' Supply and DemandChain Collaboration Practices Enabled by RFID Technology, Berlin Heidelberg:Springer-Verlag, pp. 241-256, 2005.

[2]. C. Loebbecke, "RFID technology and applications in the retail supply chain: The early metro group pilot", proceedings of 18th Bled: eConference, pp. 6-8, 2005.

[3]. Y. M. Lee, F. Cheng and Y. T. Leung, "Exploring the impact of RFID on supply chain dynamics", proceedings of '04 IEEE symposium: Winter Simulation Conference, December 2004. 
[4]. E. Hering, Investitions-und Wirtschaftlichkeitsrechnung für Ingenieure (essentials), Berlin Heidelberg:Springer-Verlag, 2014.

[5]. U. Götze and J. Bloech, Investitionsrechnung: Modelle und Analysen zur Beurteilung von Investitionsvorhaben, Berlin Heidelberg:Springer-Verlag, 1995.

[6]. Osterwalder and Y. Pigneur, Business Model Generation: A Handbook for Visionaries Game Changers and Challengers, Wiley, July 2010.

[7]. Vilkov and B. Weiß, "Wertschöpfungsnetzwerke: Konzepte für das Netzwerkmanagement und Potenziale aktueller Informationstechnologien" in Prozessorientierte Wirtschaftlichkeitsanalyse von RFID-Systemen anhand eines Referenz-Wirkungsmodells, Berlin Heidelberg:Springer-Verlag, pp. 275-303, 2008.

[8]. D. M. Hamby, "A review of techniques for parameter sensitivity analysis of environmental models", Environmental Monitoring \& Assessment, vol. 32, no. 2, pp. 135-154, 1994.

[9]. D. M. Hamby, "A comparison of sensitivity analysis techniques", Health Physics, vol. 68, no. 2, pp. 195-204, Feb 1995.

[10]. Bhamra, S. Dani and T. Bhamra, "Competence Understanding and Use in SMEs: a UK Manufacturing Perspective", International Journal of Production Research, vol. 49, pp. 2729-2743, 2011.

[11]. K. Enoch, "Lean Six Sigma Methodologies and Organizational Profitability: A Review of Manufacturing SMEs in Nigeria", American Journal of Industrial and Business Management, vol. 3, pp. 573-582, 2013.

[12]. S. M. Gnanaraj, S. R. Devadasan and K. A. G. Pandian, "Doladmics: An Excllusive Model to Implement Lean Six Sigma Paradigm in SMEs", International Journal of Operations System and Human Resource Management, vol. 1, pp. 5, 2011.

[13]. Dora, M. Kumar and X. Gellynck, "Determinants and Barriers to Lean Implementation in Food-Processing SMEs - A Multiple Case Analysis", Production Planning \& Control, vol. 27, pp. 1-23, 2015.

[14]. R. E. Gort, "Lean and Sustainability-How can they Reinforce Each Other", Master in Business Administration Management Project School of Management Bradford University School of Management Tias Nimbas Business School, 2008.

[15]. E. Nikolou-Walker and K. Lavery, "A work-based research assessment of the impact of 'lean manufacturing' on health and safety education within an SME", Research in Post-Compulsory Education, vol. 14, pp. 441-458, 2009.

[16]. S. Gupta and S. K. Jain, "A Literature Review of Lean Manufacturing", International Journal of Management Scienceand Engineering Management, vol. 8, pp. 241-249, 2013.

[17]. H. M. R. P. Herath, The Strategic Importance of Suuply Chain Management in Small and Medium Sized Enterprises- A Case study of the Garment Industry in Sri Lanka, 2014.

[18]. Mathur, M. L. Mittal and G. S. Dangayach, "Improving productivity in Indian SMEs", Production Planning \& Control, vol. 23, pp. 754$768,2012$.

[19]. D. B. Modi and H. Thakkar, "Lean Thinking: Reduction of Waste Lead Time Cost through Lean Manufacturing Tools and Technique", International Journal of Emerging Technology and Advanced Engineering, vol. 4, pp. 339-344, 2014.

[20]. L. Medbo and D. Carlsson, "Implementation of Lean in SME Experiences from a Swedish National Program", International Journal of Industrial Engineering and Management (IJIEM), vol. 4, pp. 221-227, 2013.

[21]. D. Powell, J. Riezebos and J. O. Strandhagen, "Lean Production and ERP Systems in Small- and Medium-sized Enterprises: ERP Support for Pull Production", International Journal of Production Research, vol. 51, pp. 395-409, 2013.

[22]. G. Anand and R. Kodali, "Selection of lean manufacturing systems using the analytic network process — a case study", Journal of Manufacturing Technology Management, vol. 20, pp. 258-289, 2009.

[23]. R. Shah and P. T. Ward, "Defining and Developing Measures of Lean Production", Journal of Operations Management, vol. 25, pp. 785$805,2007$.

[24]. D. T. Matt and E. Rauch, "Implementation of Lean Production in Small Sized Enterprises", Procedia CIRP, vol. 12, pp. 420-425, 2013

[25]. S. Vinodh, K. R. Arvind and M. Somanaathan, "Tools and Techniques for Enabling Sustainability Through Lean Initiatives", Clean Technologies and Environmental Policy, vol. 13, pp. 469-479, 2010.

[26]. R. K. Singh, S. K. Garg and S. G. Deshmukh, "Strategy Development by Small Scale Industries in India", Industrial Management \& Data Systems, vol. 110, pp. 1073-1093, 2010.

[27]. M. N. Rose, B. M. Deros, M. N. A. Rahman and N. Nordin, "Lean manufacturing best practices in SMEs", International Conference on Industrial Engineering and Operations Management, pp. 872-877, 2011.

[28]. S. Saad, P. Achanga, E. Shehab, R. Roy and G. Nelder, "Critical Success Factors for Lean Implementation Within SMEs", Journal of Manufacturing Technology Management, vol. 17, pp. 460-471, 2006. 